\title{
DEVELOPMENT OF A TESTING STATION FOR EMPIRICAL VERIFICATION OF THE ALGEBRAIC MODEL OF DRY ICE PISTON EXTRUSION
}

\author{
Jan GÓRECKI ${ }^{*}$ \\ *Faculty of Mechanical Engineering, Poznan University of Technology, 3 Piotrowo Street, 61-138 Poznan, Poland \\ jan.gorecki@put.poznan.pl
}

received 8 June 2020, revised 8 June 2021, accepted 15 June 2021

\begin{abstract}
Efficient use of resources is a very important consideration for every production process, especially where waste materials are used as raw materials. One example of these kinds of processes is dry ice extrusion. Based on the subject literature, it can be observed that the machines available in the market that are used to compress dry ice are characterized by high working force value. This leads to low efficiency of resource consumption, in regards to both electrical energy and carbon dioxide. This paper presents a proposed design of a test stand used for measuring compression force as a function of piston displacement in the course of the dry ice extrusion. The first part of the article presents the testing methodology and test stand design. The second part presents the results of measurement of compression force as a function of piston displacement with three different die types. The results of the study allowed to establish the difference between the values of the measured limit force and the values calculated with an analytical model. The test stand design and the results presented in this paper are important for further research and development works in the area of efficient extrusion and compaction of dry ice.
\end{abstract}

Key words: dry ice, carbon dioxide, agglomeration, extrusion, compaction

\section{INTRODUCTION}

The use of waste products from manufacturing processes is very often economically justified as it contributes to waste recovery and allows to reuse of production waste as raw material. A review of the available subject literature demonstrates the availability of insufficient information on the description of various processes applied to non-classic materials, including waste material (Wałęsa et al., 2018; Wojtkowiak et al., 2018). An example of such waste product is carbon dioxide obtained, e.g. from the manufacturing of ammonia compounds (Fig. 1); due to the large amounts of generation, factories are often unable to utilize the entire material for their needs. Consequently, liquefied carbon dioxide $\left(\mathrm{LCO}_{2}\right)$ is often sold off to interested third parties (Górecki et al., 2018; 2019a; 2019b; Uhlmann et al., 2010).

Possible applications of $\mathrm{LCO}_{2}$ include the production of dry ice. This material is obtained in solid form through decompression of the liquid. As a result of an adiabatic process, approximately $50 \%$ of the decompressed liquid gets crystallized. The resultant product's temperature is $-78.4^{\circ} \mathrm{C}$, which sublimates under normal ambient conditions (Górecki et al., 2017; Dzido et al., 2019a; Liu et al., 2012; Mazzoldi et al., 2008; Mikołajczak et al., 2018). Based on these characteristics, the material received its common name of dry ice. It is used mostly in product transportation where low temperatures are required (Dong et al., 2012; Li et al., 2016; Liu et al., 2010; Liu et al., 2017; Masa et al., 2016; Mazzoldi et al., 2008; Otto et al., 2011; Spur et al., 1999; Witte et al., 2017) and for surface cleaning (Dong et al., 2013, Dzido et al., 2019b, Dzido et al. 2021, Masa et al., 2014, Mikołajczak et al., 2018; Muckenhaupt et al., 2019).

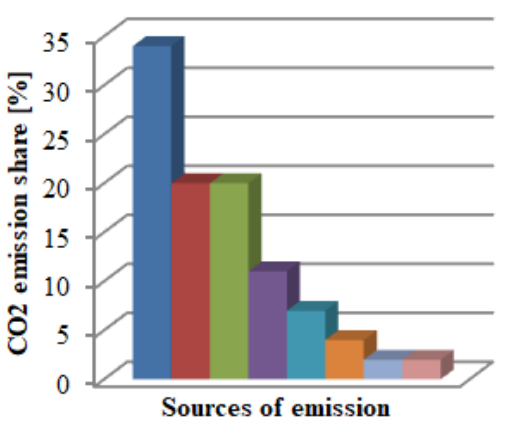

$$
\begin{aligned}
& \text { Ammonia } \\
& \text { plants } \\
& \text { Oil and gas } \\
& \text { refineries } \\
& \text { Plate tectonics } \\
& \text { - Production of } \\
& \text { ethanol } \\
& \text { Chemical } \\
& \text { processing plants } \\
& \text { 'Flue gas } \\
& \text { Production of } \\
& \text { alcohol } \\
& \text { - Other }
\end{aligned}
$$

Fig. 1. Main sources of carbon dioxide emissions by percentage share (Górecki et al., 2017)

Extrusion of agglomerated, crystallized carbon dioxide serves to reduce the surface of phase transition, which slows down sublimation and extends the time for which the material stays in solid form (Górecki et al., 2020; Liu et al., 2012).

Various equipment for dry ice extrusion are available in the machine market. The majority of offered solutions utilise piston technology with hydraulic or crank-piston drives. However, there are few sources covering the methods of extrusion or agglomeration of dry ice available in the subject literature (Górecki et al., 2019b; 2020).

Due to the identified deficiency of information regarding extrusion and agglomeration of dry ice as well as considering the peculiar characteristics of the material, it is necessary to carry out scientific works to develop an algebraic model for establishing the resistance force value in multichannel dies (Gorecki et al., 2020b). 
The model provided in this paper is verified only in the laboratory conditions. Therefore, with the intention of employing the model in an industrial environment, it is necessary to develop a suitable testing station to facilitate the study of this kind of environmental condition.

Available subject literature demonstrates a high degree of interest in works aiming to study and develop the shape of the tools used in the process with view of improving product quality as well as the energy efficiency of the process (Dudziak et al., 2017; Dzido et al., 2019a; Górecki et al. 2020a; 2020b; Ishiguro et al., 2020; Kukla et al. 2017; Malujda et al., 2016; Talaśka, 2017; Wałęsa et al., 2019a; 2019b; 2020a; 2020b; Wilczyński et al. 2018; Wilczyński et al., 2019a; 2019b; 2019c; 2020; Wojtkowiak et al. 2019; 2021).

\section{BUILDING OF THE TESTING STAND}

Fig. 2 provides an overview drawing of the testing station developed by the authors. A vessel with $\mathrm{LCO}_{2}$ kept at the pressure of $20 \mathrm{bar}$ is attached to the machine. After its decompression in working chamber 2, the material crystallises in fragmented form (Górecki et al., 2017; 2019a). Afterwards, the pneumatic actuator 1 is powered by compressed air and its piston rod 1 moves together with the piston 3 . The reduction of volume of the working chamber 2, which contains the crystallised carbon dioxide, leads to the agglomeration of the material. The compaction process continues until the force available on the piston $F_{T}$ becomes equal to the resistance force $F_{O P}$ associated with the extrusion of the material through the die channel 4 installed at the end of the working chamber 2 . After withdrawing the piston to starting position, the device is ready to begin the next work cycle.

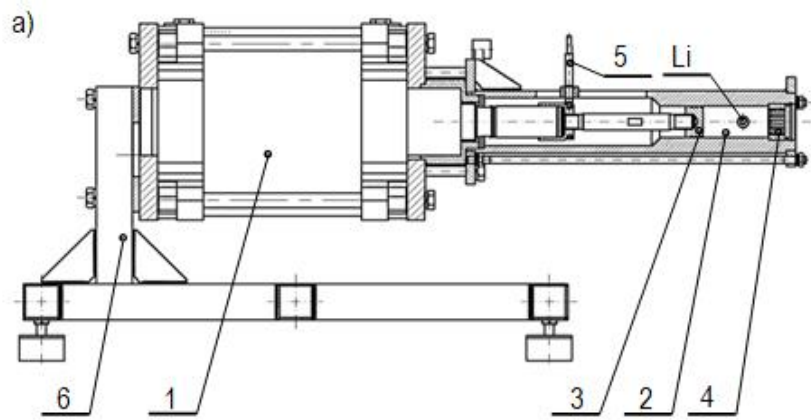

b)

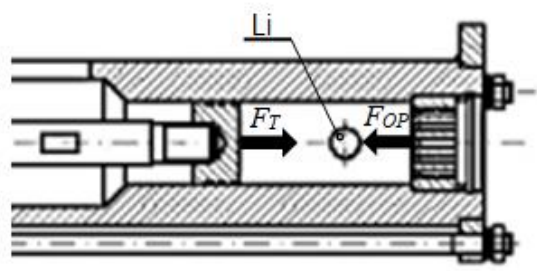

Fig. 2. The working unit of dry ice agglomeration. (a) test stand and (b) compaction assembly: 1 - pneumatic piston, 2 - working chamber, 3 - compacting piston, 4 - multi-channel die, 5 displacement sensor grip, 6 - frame. Li, -liquid inlet

The components necessary to carry out the above process that are not provided in Fig. 2 include the unit responsible for the preparation and injection of the $\mathrm{LCO}_{2}$ as well as the control and measurement instrumentation. Fig. 3 illustrates the interconnections between the indicated components.

\section{METHODOLOGY}

The testing station is equipped with suitable instrumentation to determine the change of force value applied on the piston $F_{T}$ as a function of its displacement. Fig. 3 illustrates the schematic view of the station.

The $F_{T}$ value is determined based on the signal from pressure transducers 12 and 13 placed on both sides of the actuator piston. The measurement of displacement of the compacting piston 3 is achieved by the displacement sensor 5 . The transducers are connected to the data acquisition system that includes a data amplifier 19, the signal measurement board 20 and the PC 21 .

Fig. 3 presents the automated control system for the testing station. It governs the operation of electrovalve 6 , which controls the direction of movement of actuator 1 as well as the $\mathrm{LCO}_{2}$ injection system electrovalves 11 and 7 . The programmable logic controller (PLC) 18 operates the indicated components based on the developed algorithm and signals from limit switches 16 and 17 and the vibrating level sensor 10 controlling the $\mathrm{LCO}_{2}$ level.

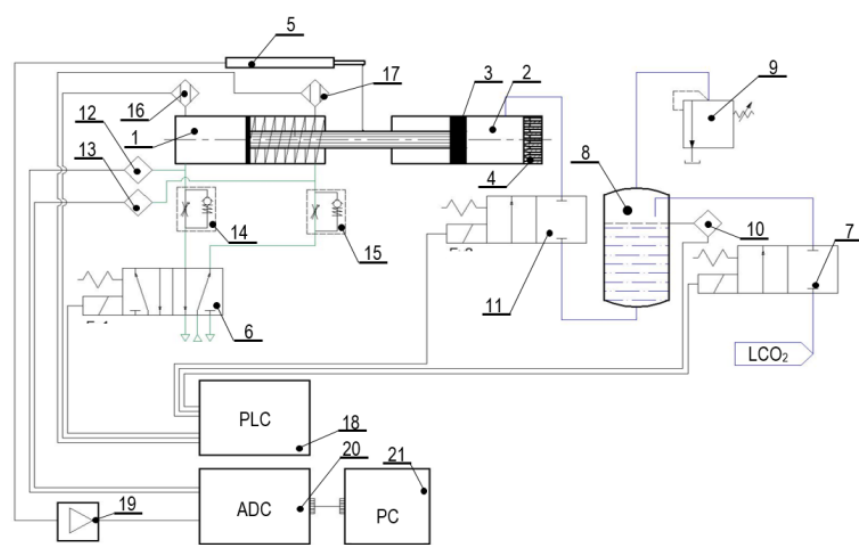

Fig. 3. Schematic view of the carbon dioxide agglomeration station: 1 - pneumatic actuator, 2 - working chamber, 3 - compacting piston, 4 - multi-channel die, 5 - WA-100 displacement sensor, 6 - type $5 / 2$ distributing electrovalve, 7 - refill electrovalve, 8 - liquid $\mathrm{CO}_{2}$ buffer container, 9 - pressure adjustment valve, 10 - vibrating level sensor for liquid presence, 11 - liquid injection electrovalve, 12,13 - pressure transducer, 14 and 15 - throttle check valve, 16 and 17 - piston end position sensor, 18 - PLC controller, 19 - measurement amplifier, 20 - signal measurement board, 21 - data acquisition PC

For the purpose of the study, three types of multichannel dies (MCD) with conical-cylindrical channels are used. Each die is characterized by different geometric parameters as provided in Tab. 1 and illustrated in Fig. 4. The die dimensions match the design features of the device, enabling the testing station to be retooled. This allows to compare results with an identical error of measurement resulting from the inaccuracy of pressure transducers equal to $0.01 \%$ of the measurement range, i.e. 10 bar. Based on the above factors, it is determined that the pressure measurement error is equal to $|\delta p|= \pm 10 \mathrm{kPa}$.

The following expression was used to determine the value of available force on the piston,

$F_{T}=\frac{\left(p_{1}-p_{2}\right) \cdot \pi \cdot\left(2 \cdot R_{K}\right)^{2}}{4}$,

where: $R_{k}$ - radius of the compacting piston, $R_{k}=18 \mathrm{~mm}$. 
Based on the formula 1, the measurement error value for force $F_{T}$ was determined using the expression as given below,

$\left|\delta_{F}\right|=\frac{\left(\left|\delta p_{1}\right|+\left|\delta p_{2}\right|\right) \cdot \pi \cdot\left(2 \cdot R_{K}\right)^{2}}{4}=20.36 \mathrm{~N}$.

The established error value for force measurement is deemed sufficiently accurate for employing type A method for result analysis, based on statistical analysis (Arendarski, 2006).

a)

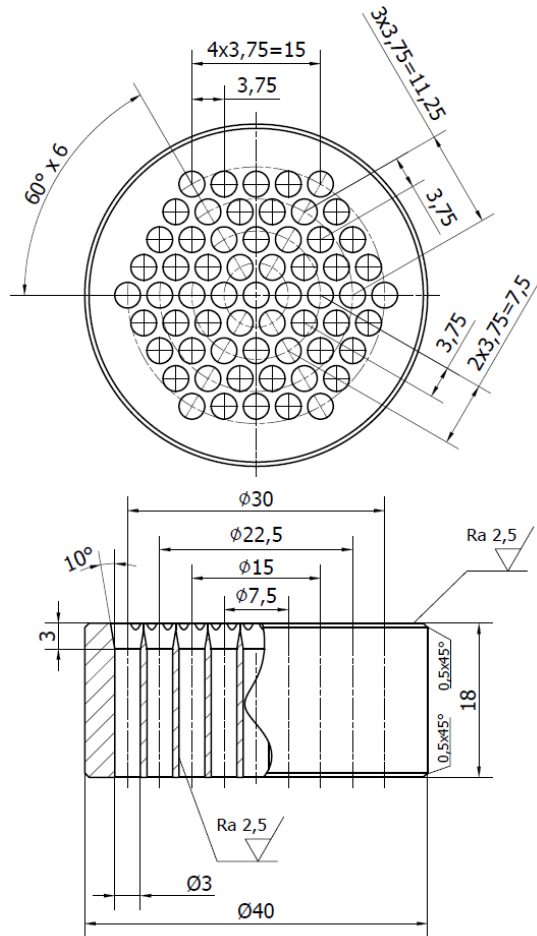

b)
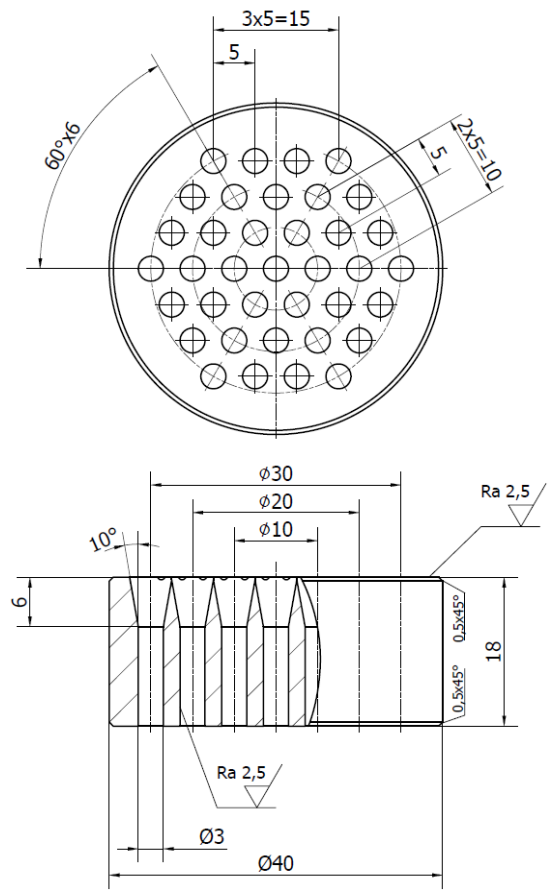

c)
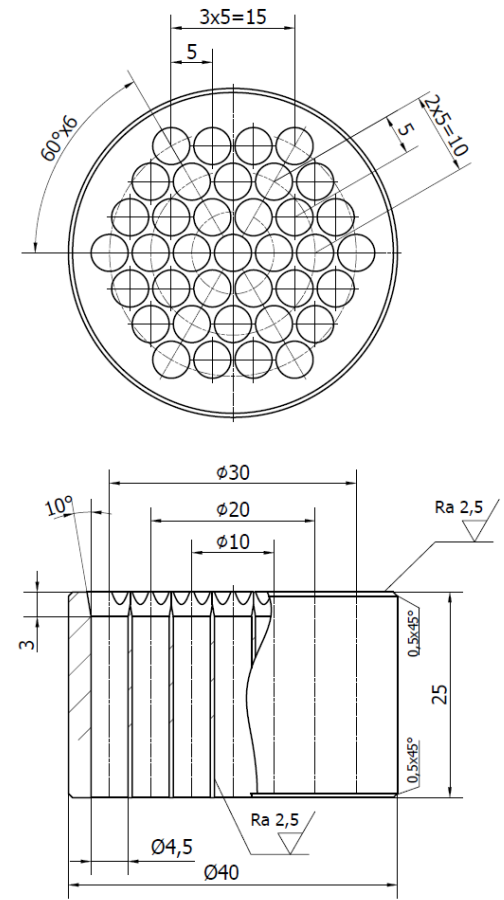

Fig. 4. Multichannel forming dies, a - MCD-0, $b-M C D-1, c-M C D-2$

Tab. 1. Geometric parameters of the multichannel forming dies, $D_{\text {out }}$ - diameter of the channel outlet, $n$ - number of channels

\begin{tabular}{|c|c|c|c|c|c|c|c|c|}
\hline & $n$ & $\begin{array}{c}D_{\text {out }} \\
{[\mathrm{mm}]}\end{array}$ & $\begin{array}{c}\alpha \\
{\left[{ }^{\circ}\right]}\end{array}$ & $\begin{array}{c}A \\
{[\mathrm{~mm}]}\end{array}$ & $\begin{array}{c}b \\
{[\mathrm{~mm}]}\end{array}$ & $\begin{array}{c}R_{K} \\
{[\mathrm{~mm}]}\end{array}$ & $\begin{array}{c}E \\
{[\mathrm{~mm}]}\end{array}$ & $n_{G}$ \\
\hline MCD-0 & 61 & 3 & \multirow{3}{*}{10} & 15 & 3 & \multirow{3}{*}{18} & 15 & 24 \\
\hline MCD-1 & 37 & 3 & & 12 & 6 & & 15 & 18 \\
\hline MCD-2 & 37 & 4.5 & & 15 & 3 & & 15 & 18 \\
\hline
\end{tabular}

\section{RESULTS}

During the examination, results are recorded from 10 consecutive dry ice extrusion process cycles. The results of the example for the die MCD-0 are provided in Fig. 5 in the form of a line graph presenting the variation of piston force $F_{T}$ as a function of displacement value $x$.

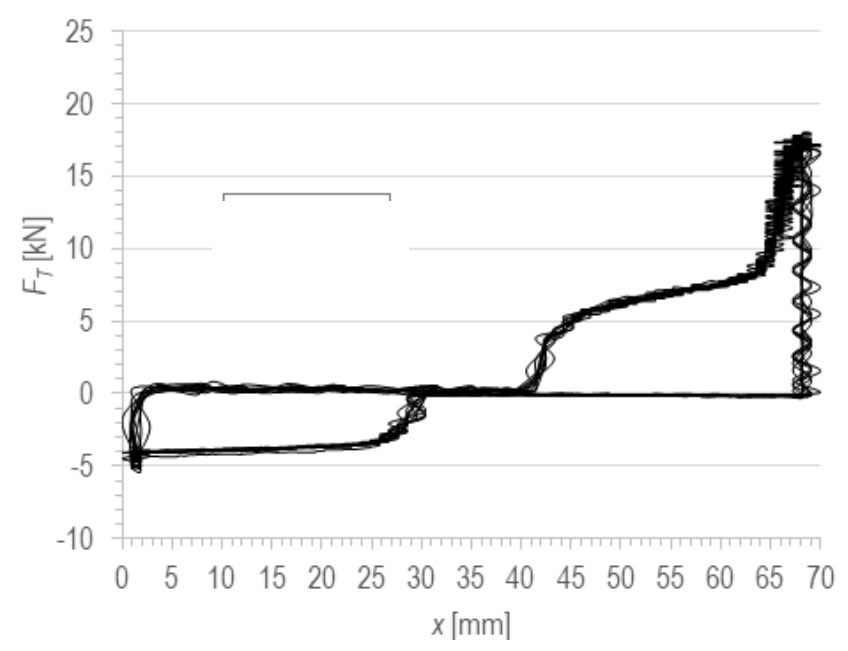

Fig. 5. Results of measuring the force applied to the piston $F_{T}$ in the course of the extrusion process using MCD- 0 die 
Development of a Testing Station for Empirical Verification of the Algebraic Model of Dry Ice Piston Extrusion

The piston withdrawal part of the cycle is excluded from the registered measurements. The results are then averaged in each of the three cases. This allows to identify the characteristics of piston force variability $F_{T}$ for each die as a function of piston displacement $x$, which are illustrated in Figs. 6-8.

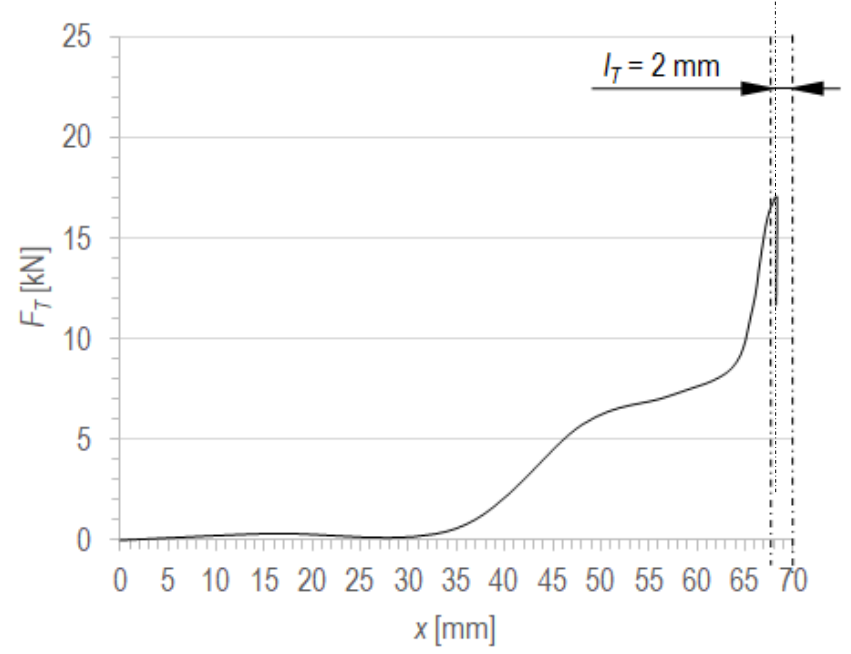

Fig. 6. The characteristic curve for force variation available on the piston $F_{T}$ as a function of piston displacement $x$ in the process of extrusion with MCD-0 die.

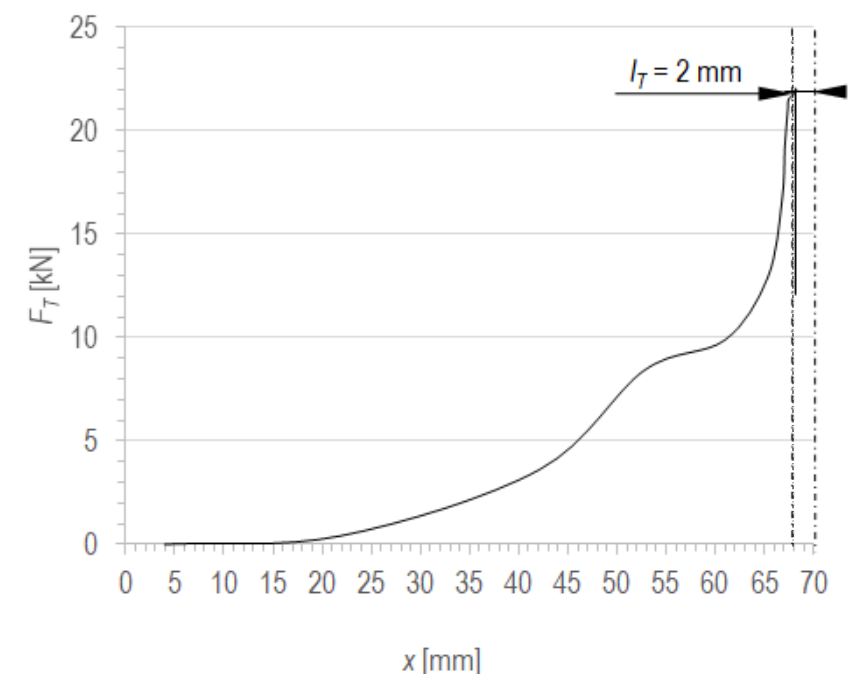

Fig. 7. The characteristic curve of the variation of force available on the piston $F_{T}$ as a function of piston displacement $x$ in the process of extrusion with MCD-1 die.

Based on the developed characteristics, the length of section $I_{T}$ in the moment of extrusion of the agglomerated material through the die is determined. This parameter has a significant influence on the $F_{O P}$ value and describes the length of agglomerated material along the axis of rotation of the compaction chamber. The influence of this parameter is described in the available literature (Górecki et al. 2017b). The value of limit force during the process utilising MCD-1 die is much higher than that in the processes employing MCD-0 and MCD-2 dies. One of the differences between MCD-0, MCD-1, and MCD-2 die types is the value of parameter $b$, which influences the shearing stress value as provided in the subject literature (Górecki et al. 2017b; Górecki 2020; Górecki et al. 2020b). Furthermore, the channel outlet diameter
Dout influences the value of the limit force. The Dout parameter relates to the value of cutting edge on the die inlet as well as the force of extrusion resistance. At the beginning of the product formation part of the process, each die channel will shear the agglomerated block of dry ice. The cutting edge parameters relate to the number of channels and the value of $D_{\text {out }}$.

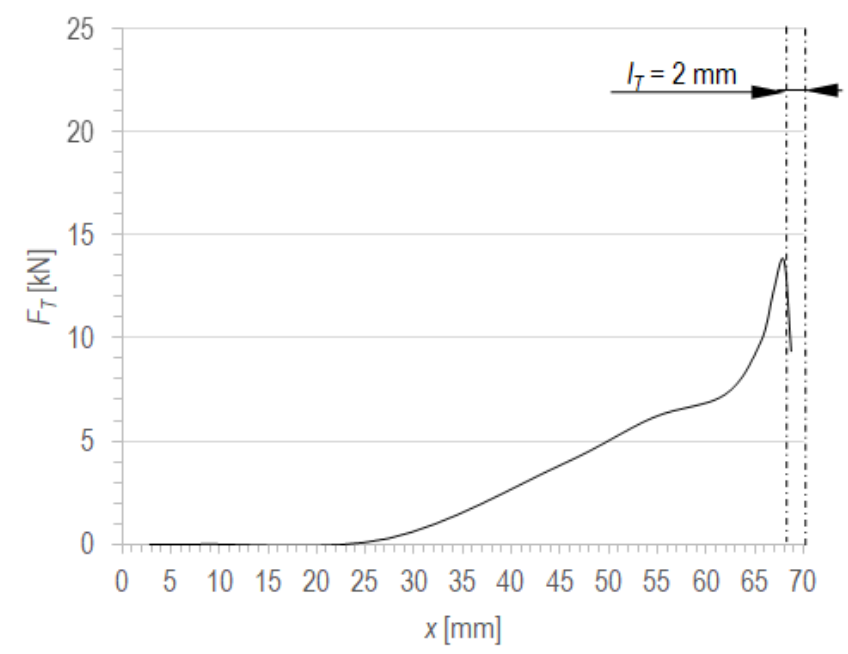

Fig. 8. The characteristic curve of the variation of force available on the piston $F_{T}$ as a function of piston displacement $x$ in the process of extrusion with MCD-2 die.

Test results allowed for comparison of the average limit force value on the piston $F_{T}^{\text {avr }}$ measured during the examination and the results obtained from the algebraic model available in subject literature (Górecki, 2020), which describes the variance of $F_{O P}$ as a function of the geometric parameters of multi-channel dies. See Table 2 for the calculated results together with the maximum measured force value on the piston $F_{T}^{a v r}$. The information regarding the percentage difference in the force value determined via the algebraic method $F_{O P}$, and the limit value $F_{T}^{a v r}$ is also provided therein. The value of the difference is calculated using the formula below.

$\delta=\frac{F_{T}^{a v r}-F_{O P}}{F_{T}^{a v r}} \cdot 100 \%$

Tab. 2. Results of measurement and analytic calculations

\begin{tabular}{|c|c|c|c|}
\hline Die model & MCD-0 & MCD-1 & MCD-2 \\
\hline$F_{o P}[\mathrm{kN}]$ & 14.2 & 16 & 10.6 \\
\hline$F_{T}^{\text {avr }}[\mathrm{kN}]$ & 17.2 & 21.9 & 14.2 \\
\hline$I_{T}[\mathrm{~mm}]$ & 2 & 2 & 2 \\
\hline$\delta[\%]$ & 17.4 & 26.94 & 25.35 \\
\hline
\end{tabular}

For all three dies, the value does not exceed $27 \%$.

\section{SUMMARY}

The article presents the results of design works on the testing station, the developed methodology and study results. The examination focussed on identifying the characteristics of force variation on the agglomerating piston as a function of its displacement. 
The obtained characteristics are used to determine the limit value of compacting force in industrial conditions. Consequently, the test results could be compared with the results derived from the algebraic model available in the subject literature (Górecki, 2020), which is used to determine the indicated force limit value based on the geometric parameters of multi-channel dies. This allows to determine the difference between results achieved in empirical testing and results derived from the algebraic model available in subject literature, the difference is expressed as a percentage value.

The difference between the calculated and the actual value of the resistance force $F_{O P}$ is affected by the dosing accuracy of the $\mathrm{LCO}_{2}$, the efficiency of the crystallisation process as well as the resistances effected by the displacement of the agglomerating piston in the device working chamber. According to published studies, the difference in the value derived from the model and the verification tests in laboratory conditions is up to $12.9 \%$. The differences between the algebraic calculation and measurement results obtained from the author's prototype carbon dioxide agglomeration machine are therefore justified. The test result analysis allows to demonstrate that the geometrical parameters of dies influence the limit force during the extrusion process.

The paper presented basic observations regarding the influence of geometrical parameters of multichannel dies on the limit force, which are in line with the conclusion of previous research (Górecki et al, 2019a; Górecki, 2020; Górecki et al. 2020b).

\section{REFERENCES}

1. Arendarski $\mathbf{J}$ (2006), Measurement uncertainty (in Polish), Warsaw University of Technology Publisher.

2. Dudziak M, Kołodziej A, Domek G., et al. (2017), Multi-angularity identification of parameters and compatibility conditions of the axisymmetric connection with form deviations Procedia Engineering vol. $177431-438$

3. Dong S., Song B., Hansz B., et al. (2012), Modeling of dry ice blasting and its application in thermal spray, Material Research Innovations, Vol. 16, 61-66.

4. Dong S., Song B., Hansz B., et al., (2013), Combination Effect of Dry-Ice Blasting and Substrate Preheating on Plasma-Sprayed CoNiCrAlY Splats, Journal of Thermal Spray Technology, Vol. 22, No. 1, https://doi.org/10.1007/s11666-012-9845-z.

5. Dzido A., Krawczyk P., Kurkus-Gruszecka M., et al. (2019) Analysis of the Liquid Natural Gas Energy Storage basing on the mathematical model, Energy Procedia, Vol. 159, 231-236.

6. Dzido A., Krawczyk P., Kurkus-Gruszecka M. (2019), Numerical Analysis of Dry Ice Blasting Convergent-Divergent Supersonic Nozzle, Energies, Vol. 12, 4787.

7. Dzido A., Krawczyk., Badyda K., Chondrokostas, (2021), Operational parameters impact on the performance of dry-ice blasting nozzle, Energy, Vol. 214, https://doi.org/10.1016/j.energy. 2020.118847

8. Górecki J., Malujda I., Talaśka K., et al. (2015) Static compression tests of concentrated crystallized carbon dioxide, Applied Mechanics and Materials, Vol. 816, 490-495.

9. Górecki J., Malujda I., Talaśka K., et al. (2017), Dry ice compaction in piston extrusion process, Acta mechanica et automatic, Vol. 11, no. $4,313-316$

10. Górecki J., Malujda I., Talaśka K., et al. (2017), Influence of the compression length on the ultimate stress in the process of mechanical agglomeration of dry ice, Procedia Engineering, vol. 177 363-368.

11. Górecki J., Malujda I., Wilczyński D. (2019), The influence of geometrical parameters of the forming channel on the boundary value of the axial force in the agglomeration process of dry ice, Matec Web of Conferences, Vol.254, 05001.

12. Górecki J., Malujda I., Wilczyński D., Wojtkiak D. (2019), Influence of the face surface shape of the piston on the limit value of compaction stress in the process of dry ice agglomeration, Matec Web of Conferences, Vol.254, 2019, 06001.

13. Górecki J., (2020), Preliminary analysis of the sensitivity of the algebraic dry ice agglomeration model using multi-channel dies to change their geometrical parameters, IOP Conference Series: Materials Science and Engineering, 776, 012030.

14. Górecki J., Fierek A., Talaśka K., et al., (2020), The influence of the limit stress value on the sublimation rate during the dry ice densification process, IOP Conference Series: Materials Science and Engineering, 776, 012072.

15. Górecki J., Talaśka K., Wałęsa K., et al., (2020), Mathematical Model Describing the Influence of Geometrical Parameters of Multichannel Dies on the Limit Force of Dry Ice Extrusion Process, Materials, vol. 13(15), 3317-1 - 3317-11.

16. Ishiguro M., Dan K., Kaneko S., et al. (2020) Snow Consolidation Properties by using Mechanical Press Machine, Journal of the Institute of Industrial Applications Engineers, Vol. 7(3), 83-90.

17. Kukla M, Górecki J, Malujda I, et al. (2017) The determination of mechanical properties of magnetorheological elastomers (MREs) Procedia Engineering, vol. 177 324-330.

18. Li M., Liu W., Qing X., et al. (2016), Feasibility study of a new approach to removal of paint coatings in remanufacturing, Journal of Materials Processing Technology, Vol. 234, 102-112.

19. Liu Y., Calvert G., Hare C., et al. (2012), Size measurement of dry ice particles produced from liquid carbon dioxide, Journal of Aerosol Science, Vol. 48, 1-9.

20. Liu Y., Hirama D., Matusaka S. (2017), Particle removal process during application of impinging dry ice jet, Powder Technology, 607613.

21. Liu Y., Maruyama H., Matsusaka S. (2010), Agglomeration process of dry ice particles produced by expanding liquid carbon dioxide, Advanced Powder Technology, Vol. 21, 652-657.

22. Malujda I., Wilczyński D., (2016) Mechanical Properties Investigation of Natural Polymers, Procedia Engineering vol. 136, 263-268.

23. Masa V., Kuba P., Perilak D., Lokaj J., (2014), Decrease in Consumption of Compressed Air in Dry Ice Blasting Machine, Chemical Engineering Transactions, 39, 805-810, https://doi.org/10. 3303/CET1439135.

24. Masa V., Kuba P. (2016), Efficient use of compressed air for dry ice blasting, Journal of Cleaner Production, Vol. 111, 76-84

25. Mazzoldi A., Hill T., Colls J. (2008), CO2 transportation for carbon capture and storage: Sublimation of carbon dioxide from a dry ice bank, International Journal of Greenhouse Gas Control, Vol. 2, 210-218

26. Mikołajczak A., Krawczyk P., Stępień M., et al. (2018), Preliminary specification of the dry ice blasting converging-divergent nozzle parameters basing on the standard (analytical) methods, Rynek Energii, Vol. 4, 91-96.

27. Muckenhaupt D., Zutzmann T., Rudek A., Russ G., (2019), An Experimental and Numerical Procedure for Energetic and Acoustic Optimization of Dry-ice Blasting Processes, Chemical Engineering Transactions, Vol. 74, 967-972, https://doi.org/10.3303/CET1974162

28. Otto C., Zahn S., Rost F., et al. (2011), Physical Methods of cleaning And Disinfection of Surfaces, Food Engineering Review, Vol. 3, 171-188.

29. Talaśka K., (2017), Analysis of the energy efficiency of the shredded wood material densification process Procedia Engineering 177 352357.

30. Spur G., Uhlmann E., Elbing F. (1999), Dry-ice blasting for cleaning: process, optimization and application, Wear, Vol. 233-235, 402-411.

31. Uhlmann E., Kretzschmar M., Elbing F., et al. (2010), Deburring with $\mathrm{CO} 2$ Snow Blasting. In: J. Aurich, D. Dornfeld (eds) Burrs Analysis, Control and Removal. Springer, Berlin, Heidelberg. 
32. Wałęsa K., Malujda I., Talaśka K. (2018), Butt welding of round drive belts, Acta Mechanica et Automatica, Vol. 12, no. 2, s. 115-126

33. Wałęsa K., Malujda M., Górecki J., et al. (2019), The temperature distribution during heating in hot plate welding process, MATEC Web of Conferences, Vol. 254, 0233-1 - 02033-11.

34. Wałęsa K., Malujda I., Wilczyński D. (2019), Shaping the parameters of cylindrical belt surface in the joint area, Acta Mechanica et Automatica, vol. 13, 255-261.

35. Wałęsa K., Malujda I., Wilczyński D. (2020), Experimental research of the thermoplastic belt plasticizing process in the hot plate welding, IOP Conference Series: Materials Science and Engineering, 776, 012011.

36. Wałęsa K., Malujda I., Górecki J. (2020), Experimental research of the mechanical properties of the round drive belts made of thermoplastic elastomer, IOP Conference Series: Materials Science and Engineering, 776, 012107.

37. Wilczyński D., Talaśka K., Malujda I., et al. (2018) Experimental research on biomass cutting process MATEC Web of Conferences vol. 15707016.

38. Wilczyński D, Berdychowski M, Wojtkowiak D, et al. (2019) Experimental and numerical tests of the compaction process of loose material in the form of sawdust, MATEC Web of Conferences, vol. 25402042.

39. Wilczyński D., Malujda I., Górecki J. et al. (2019) Experimental research on the process of cutting transport belts, MATEC Web of Conferences, vol. 25405014.
40. Wilczyński D., Malujda l., Górecki J., et al., (2019) Research on the process of biomass compaction in the form of straw, MATEC Web of Conferences, vol. 25405015.

41. Wilczyński D., Wałęsa K., Berdychowski M., et al., (2020) Biomass cutting tests to determine the lowest value of the process force, IOP Conf. Series: Materials Science and Engineering vol. 776012014.

42. Witte A., Bobal M., David R., et al. (2017), Investigation of the potential of dry ice blasting for cleaning and disinfection in the food production environment, LWT - Food Science and Technology, Vol. $75,735-741$.

43. Wojtkowiak D., Talaśka K., Malujda I., et al. (2018), Estimation of the perforation force for polymer composite conveyor belts taking into consideration the shape of the piercing punch. The International Journal of Advanced Manufacturing Technology https://doi.org/10. 1007/s00170-018-2381-3.

44. Wojtkowiak D. and Talaśka K. (2019) Determination of the effective geometrical features of the piercing punch for polymer composite belts The International Journal of Advanced Manufacturing Technology, vol. 104, 315-332.

45. Wojtkowiak D., Talaśka K., Wilczyński D., et al. (2021), Determining the Power Consumption of the Automatic Device for Belt Perforation Based on the Dynamic Model. Energies, Vol. 14, No. 1, http://dx.doi.org/10.3390/en14020317.

Jan Górecki: (D) https://orcid.org/0000-0002-4640-7418 